p-ISSN:2302-4224 ; e-ISSN:2685-1083
Jumal Matematika dan Aplikasi
J o u r n a l h o m e p a g e: https://ejournal.unsrat.ac.id/index.php/decartesian

\title{
Analisis Portofolio Saham Model Markowitz Dengan Menggunakan Quadratic Programming
}

\author{
Shintya Gayanti Filrissa ${ }^{1}$, Jullia Titaley ${ }^{1}$, Tohap Manurung1* \\ ${ }^{1}$ Jurusan Matematika-Fakultas Matematika dan Ilmu Pengetahuan Alam-Universitas Sam Ratulangi Manado, Indonesia
}

${ }^{*}$ Corresponding Author : Tohapm@ unsrat.ac.id

\begin{abstract}
ABSTRAK
Dalam investasi saham para investor harus memperhatikan dua hal yaitu tingkat keuntungan dan tingkat kerugian atau resiko. Expected return dan resiko memiliki hubungan yang positif. Seorang investor diharapkan dapat membentuk portofolio yang optimal dalam berinvestasi, dengan tujuan meminimumkan resiko dengan tingkat keuntungan tertentu. Penelitian ini bertujuan untuk menentukan portofolio optimal, dengan metode penyelesaian yang digunakan yaitu quadratic programming. Data yang digunakan adalah saham Indeks Kompas 100. Hasil penelitian menunjukkan portofolio optimal didapat dengan mengalokasikan sejumlah dana dengan bobot $(w)$ tertentu pada 66 saham yang ada di Indeks Kompas 100.
\end{abstract}

\section{INFO ARTIKEL}

Diterima : 16 Juli 2019

Diterima setelah revisi : 23 Juli 2019

Tersedia online : 25 Juli 2019

\section{Kata Kunci}

Saham

Portofolio Model Markowitz

Tingkat Keuntungan

Resiko

Bobot

Pemrograman kuadratik

\section{ABSTRACT}

Investing in shares for investors pays attention to two things, the level of profit and the level of loss ar risk. Expected return and risk have a positive relationship. An inverstos can form an optimal portfolio of investments. With the aim of minimizing risk with a certain level of profit. This study aims to determine the optimal portfolio, with the solution methodused is quadratic programming. With the data used are the Index Kompas 100 shares. From the result of optimal portfolio research obtained by investing a number of funds with a certain weight (w) on 66 shares in the Index Kompas 100.

\section{ARTICLE INFO}

Accepted : 16 July 2019

Accepted after revision : 23 July 2019

Available online : 25 July 2019

Keyword
Stock
Markowitz Model Portfolio
Level of risk
Risk
Weight
Quadratic programming

\section{PENDAHULUAN}

Investasi merupakan suatu kegiatan penempatan dana pada aset produktif dengan harapan mendapat pertumbuhan modal (capital growth) dalam jangka waktu tertentu. Orang yang melakukan investasi disebut investor. Dalam melakukan investasi, seorang investor diharapkan mampu membentuk portofolio. Portofolio merupakan gabungan atau kombinasi dari beberapa aset, baik berupa aset finansial maupun aset riil yang dimiliki oleh investor[1]. Dengan portofolio diharapkan investor mendapatkan keuntungan yang optimal dengan mempertimbangkan expected return (harapan keuntungan atau tingkat pengembalian) dan resiko.

Harry M. Markowitz di tahun 1950-an pertama kali memperkenalkan konsep dari resiko portofolio dengan menggabungkan beberapa sekuritas tunggal kedalam bentuk portofolio. Portofolio optimal merupakan portofolio yang dipilih seorang investor dari sekian banyak pilihan yang ada pada kumpulan portofolio yang efisien. Portofolio dikategorikan efisien apabila memiliki tingkat resiko yang sama, mampu memberikan tingkat keuntungan yang lebih tinggi, ataupun mampu menghasilkan tingkat keuntungan yang sama, tetapi dengan resiko yang lebih rendah.

Analisis portofolio optimal dapat dilakukan dengan berbagai cara. Pada penelitian ini penulis memilih untuk menyelesaikan masalah pembentukkan portofolio saham tersebut dengan menggunakan metode optimasi kuadratik atau biasa dikenal dengan pemrograman kuadratik (quadratic programming). Data yang diambil adalah data harga saham Indeks Kompas 100 selama periode 1 tahun yaitu dari September 2015 sampai September 2016. Data harga saham berupa harga penutupan (close price) saham harian.

\section{Pengertian Dan Harga Saham}

saham merupakan bukti kepemilikan atas suatu perusahaan dan pemilik saham berhak atas keuntungan dari perusahaan dan besarnya keuntungan tersebut trergantung dari besar jumlah saham yang dimiliki. 
Harga saham merupakan salah satu indikator pengelolaan perusahaan [2].

\subsection{Pengertian Investasi}

Menurut [2] investasi adalah komitmen atas sejumlah dana atau sumber daya lainnya yang dilakukan pada saat ini, dengan tujuan memperoleh sejumlah keuntungan di masa datang. Pihak yang melakukan kegiatan investasi disebut investor. Seorang investor membeli sejumlah saham saat ini dengan harapan memperoleh keuntungan dari kenaikan harga saham maupun sejumlah dividen di masa yang akan datang.

\subsection{Pengertian Portofolio}

Portofolio adalah serangkaian kombinasi beberapa sekuritas yang diinvestasikan dan dipegang oleh investor, baik perorangan maupun lembaga. Portofolio efisien adalah memaksimalkan expected return dengan tingkat resiko tertentu, atau portofolio yang menawarkan resiko rendah dengan expected return tertentu [3].

\subsection{Return}

Return merupakan hasil yang diperoleh dari investasi. Return dapat berupa return realisasi (realized return) yang sudah terjadi. untuk investasi, termasuk digunakan sebagai data analisis portofolio. Return realisasi dihitung dengan menggunakan data historis. Return realisasi portofolio adalah rata-rata tertimbang dari return realisasi setiap aset tunggal di dalam portofolio [4]. Secara sistematis untuk n-aset, return realisasi portofolio dapat ditulis:

$\overline{r_{p}}=\sum_{i=1}^{n}\left(w_{i} \cdot \bar{r}_{i}\right)$

Keterangan:

$$
\begin{array}{ll}
\bar{r}_{p} & =\text { return realisasi portofolio } \\
w_{i} & =\text { bobot yang diinvestasikan pada saham } i \\
\bar{r}_{l} & =\text { return realisasi dari aset ke- } i \\
n & =\text { jumlah dari aset tunggal }
\end{array}
$$

\subsection{Expected Return}

Menurut [4] return ekspektasi (expected return) merupakan return yang diharapkan dari investasi yang akan dilakukan. Return ekspektasi merupakan return yang penting karena dapat digunakan sebagai pengambilan keputusan investasi.

a) Expected return saham individual

$$
E\left(r_{i}\right)=\frac{\sum_{t=1}^{n} r_{i t}}{n}
$$

Keterangan :

$E\left(r_{i}\right) \quad=$ nilai return ekspektasi

$r_{i t} \quad=$ return aset ke-i pada periode ke-t

$n=$ banyaknya return yang terjadi pada periode observasi

b) Expected return portofolio

$E\left(\overline{r_{p}}\right)=\sum_{i=1}^{n}\left(w_{i} \cdot E\left(\overline{r_{l}}\right)\right)$

Keterangan:

$E\left(\bar{r}_{p}\right) \quad=$ return ekspektasi dari portofolio

$w_{i} \quad=$ proporsi dari aset ke- $i$ terhadap seluruh aset di portofolio

$E\left(\bar{r}_{l}\right) \quad=$ return ekspektasi dari aset ke- $i$

$n=$ banyaknya return yang terjadi pada periode observasi

\subsection{Resiko}

Menurut [1], resiko didefinisikan sebagai besarnya penyimpangan antara tingkat pengembalian yang diharapkan (expected return) dengan tingkat pengembalian yang dicapai secara nyata (realized return). Pengukuran yang digunakan untuk menghitung resiko adalah varians [5].

a) Resiko saham individual

$\sigma_{i}^{2}=\frac{\sum_{j=1}^{n}\left(r_{i t}-E\left(r_{i}\right)\right)^{2}}{n}$

Keterangan:

$\sigma_{i}^{2} \quad=$ varians dari investasi pada saham $i$

$E\left(r_{i}\right) \quad=$ nilai harapan return aktiva ke- $i$

$r_{i t} \quad=$ return aset ke-i pada periode ke- $t$

$n \quad=$ banyaknya return yang terjadi pada periode observasi

b) Resiko portofolio

$\sigma_{p}^{2}=\sum_{i=1}^{n} w_{i}^{2} \sigma_{i}^{2}+\sum_{i=1}^{n} \sum_{\substack{j=1 \\ i \neq j}}^{n} w_{i} w_{j} \sigma_{i j}$

$\sigma_{p}^{2}=\sum_{i=1}^{n} \sum_{j=1}^{n} w_{i} w_{j} \sigma_{i j} \quad$ dimana $\sigma_{i i}=\sigma_{i}^{2}$

Keterangan:

$\sigma_{p}^{2} \quad=$ resiko portofolio

$w_{i} \quad=$ bobot yang diinvestasikan pada saham $i$

$w_{j} \quad=$ bobot yang diinvestasikan pada saham $j$

$\sigma_{i}^{2} \quad=$ varians dari investasi pada saham $i$

$\sigma_{i j} \quad=$ kovarian return antara saham

\subsection{Divertifikasi}

Untuk meminimumkan resiko, perlu dilakukan diversifikasi dalam berinvestasi, yaitu membentuk portofolio atau meng-investasikan dana tidak hanya disatu asset saja melainkan beberapa asset.

\subsection{Model Mean Varians Markowitz}

Harry Markowitz untuk menentukan portofolio yang optimal, ia mengidentifikasi expected return dan resiko menggunakan varians return, dimana varians tersebut diminimalkan untuk tingkat ekpektasi tertentu. Dengan demikian portofolio optimasi menggunakan model mean-variance Markowitz sebagai berikut :

Fungsi tujuan:

minimumkan $\sigma_{p}^{2}=\sum_{i=1}^{n} \sum_{j=1}^{n} w_{i} w_{j} \sigma_{i j}$

dengan kendala:

$\sum_{i=1}^{n} w_{i}=1$
$\sum_{i=1}^{n} w_{i} \bar{r}_{l}=\bar{r}_{p}$

dimana $w_{i} \geq 0$ untuk $i=1,2, \ldots, n$ dan jumlah proporsi dana sama dengan satu.

\subsection{Pemrograman Non Linier}

Tidak semua permasalahan dalam kehidupan sehari-hari bisa diselesaikan dengan pemrograman linier. Oleh karena itu munculah pemrograman nonlinier. Bentuk umum masalah non linier adalah menentukan nilai dari variabel keputusan $x_{1}, x_{2}, x_{3}, \ldots, x_{n}$ agar

Maksimumkan (atau minimumkan) $Z=f\left(x_{1}, x_{2}, \ldots, x_{n}\right)$ Dengan kendala

$$
\begin{array}{clc}
g_{1}\left(\left(x_{1}, x_{2}, \ldots, x_{n}\right)\right. & (\leq,=\text { atau } \geq) & b_{1} \\
g_{2}\left(\left(x_{1}, x_{2}, \ldots, x_{n}\right)\right. & (\leq,=\text { atau } \geq) & b_{2} \\
& \vdots & \\
g_{m}\left(\left(x_{1}, x_{2}, \ldots, x_{n}\right)\right. & (\leq,=\text { atau } \geq) & b_{m}
\end{array}
$$


Dimana $f$ fungsi non linier dan $g$ fungsi linier atau non linier [6].

\subsection{Matriks Hessian}

Matriks Hessian adalah matriks yang setiap elemennya dibentuk dari turunan parsial kedua dari suatu fungsi. Misalkan $f(x)$ suatu fungsi dengan $n$ variabel, maka matriks Hessian dari $f(x)$ yaitu:

$H=\left[\begin{array}{cccc}\frac{\partial^{2} f}{\partial x_{1}{ }^{2}} & \frac{\partial^{2} f}{\partial x_{1} \partial x_{2}} & \cdots & \frac{\partial^{2} f}{\partial x_{1} \partial x_{n}} \\ \frac{\partial^{2} f}{\partial x_{1} \partial x_{2}} & \frac{\partial^{2} f}{\partial x_{2}{ }^{2}} & \cdots & \frac{\partial^{2} f}{\partial x_{2} \partial x_{n}} \\ \vdots & \vdots & \ddots & \vdots \\ \frac{\partial^{2} f}{\partial x_{n} \partial x_{1}} & \frac{\partial^{2} f}{\partial x_{n} \partial x_{2}} & \cdots & \frac{\partial^{2} f}{\partial x_{n}{ }^{2}}\end{array}\right]$

\subsection{Pemrograman Kuadratik (Quadratic Programming)}

Menurut [7] pemrograman kuadratik merupakan pendekatan permasalahan optimasi nonlinier dimana kendalanya berupa fungsi linier dan fungsi tujuannya merupakan kuadrat dari variable keputusan ataupun perkalian dari dua variable keputusan. Bentuk dari masalah kuadratik adalah sebagai berikut:

Meminimumkan $f(x)=C^{T} X+\frac{1}{2} X^{T} H X$

Dengan kendala:

$A X(\leq$ atau $\geq) B$

$X \geq 0$

Adapun $H$ merupakan matriks simetris yang tersusun dari nilai $q_{i j}$. Dimana $q_{i j}$ merupakan hasil turunan parsial kedua terhadap $x_{i}$ dan $x_{j}$ dari fungsi tujuan. Matriks $H$ yang merupakan matriks simetris sehingga nilai $q_{i j}=q_{j i}$. Persamaan kuadratik diatas jika ditransformasikan kedalam bentuk aljabar maka akan menjadi

$$
\begin{aligned}
& F(X)=C^{T} X+\frac{1}{2} X^{T} H X \\
& F(X)=\sum_{j=1}^{n} c_{j} x_{j}+\frac{1}{2} \sum_{i=1}^{n} \sum_{j=1}^{n} q_{i j} x_{i} x_{j}
\end{aligned}
$$

\section{METODOLOGI}

Data dalam penelitian ini adalah data sekunder tentang perusahaan yang terdapat pada saham Indeks Kompas 100 sesuai surat edaran Bursa Efek Indonesia (BEI). Data yang diambil adalah data harga saham penutupan (close price) harian saham selama periode September 2015 - September 2016. Prosedur penelitian yang dilakukan sebagai berikut:

1. Mengumpulkan data daftar saham (perusahaan) yang terdaftar di Indeks Kompas 100 sesuai dengan surat edaran dari Bursa Efek Indonesia (BEI) selama periode yang ditentukan.

2. Mengumpulkan harga penutupan (close prise) masing-masing saham.

3. Menghitung return, expected return, varians, standar deviasi, dan kovarians saham.

4. Menentukan formulasi portofolio Markowitz.

5. Mengubah formulasi portofolio ke dalam formulasi program kuadratik (quadratic programming).

6. Menyelesaikan formulasi program kuadratik dengan bantuan software matematika.

\section{HASIL DAN PEMBAHASAN}

\subsection{Data Saham Indeks Kompas 100}

Berdasarkan surat edaran BEI pada Indeks Kompas 100 selama periode September 2015 sampai September 2016 yang diambil dari website resmi Bursa Efek Indonesia (BEI) www.idx.co.id, diperoleh data saham yang tetap selama periode tersebut diuraikan pada table dibawah ini.

\begin{tabular}{|c|c|c|c|}
\hline No & $\begin{array}{l}\text { Kode } \\
\text { Saham } \\
\end{array}$ & Nama Perusahaan & Status \\
\hline 1 & AALI & Astra Agro Lestari Tbk & Tetap \\
\hline 2 & ACES & Ace Hardware Indonesia Tbk & Tetap \\
\hline 3 & $\mathrm{ADHI}$ & Adhi Karya (Persero) Tbk & Tetap \\
\hline 4 & $\mathrm{ADRO}$ & Adaro Energy Tbk & Tetap \\
\hline 5 & AISA & Tiga Pilar Sejahtera Food Tbk & Tetap \\
\hline 6 & AKRA & AKR Corporindo Tbk & Tetap \\
\hline 7 & ANTM & Aneka Tambang (Persero) Tbk & Tetap \\
\hline 8 & APLN & Agung Podomoro Land Tbk & Tetap \\
\hline 9 & ASII & Astra International Tbk & Tetap \\
\hline 10 & ASRI & Alam Sutera Reality Tbk & Tetap \\
\hline 11 & BBCA & Bank Central Asia Tbk & Tetap \\
\hline 12 & BBNI & Bank Negara Indonesia (Persero) Tbk & Tetap \\
\hline \multirow[t]{2}{*}{13} & \multirow[t]{2}{*}{ BBRI } & Bank Rakyat Indonesia (Persero) Tbk & Tetap \\
\hline & & Bank Tabungan Negara (Persero) & Tetap \\
\hline 14 & BBTN & Tbk & \\
\hline 15 & BCIP & Bumi Citra Permai Tbk & Tetap \\
\hline 16 & BDMN & PT Bank Danamon Indonesia Tbk & Tetap \\
\hline 17 & BEST & Bekasi Fajar Industrial Estate Tbk & Tetap \\
\hline 18 & BHIT & MNC Investama Tbk & Tetap \\
\hline 19 & BJBR & BPD Jawa Barat dan Banten Tbk & Tetap \\
\hline 20 & BJTM & BPD jawa Timut Tbk & Tetap \\
\hline 21 & BKSL & Sentul City Tbk & Tetap \\
\hline 22 & BMRI & Bank Mandiri (Persero) Tbk & Tetap \\
\hline 23 & BMTR & Global Mediacom Tbk & Tetap \\
\hline 24 & BSDE & Bumi Seprong Damai Tbk & Tetap \\
\hline 25 & BUMI & PT Bumi Resources Tbk & Tetap \\
\hline 26 & BWPT & Eagle High Plantations Tbk & Tetap \\
\hline 27 & CPIN & Charoen Pokphand Indonesia Tbk & Tetap \\
\hline 28 & CTRA & Ciputra Development Tbk & Tetap \\
\hline 29 & DILD & Intiland Development Tbk & Tetap \\
\hline 30 & ELSA & Elnusa Tbk & Tetap \\
\hline 31 & EXCL & XL Axiata Tbk & Tetap \\
\hline 32 & GGRM & Gudang Garam Tbk & Tetap \\
\hline 33 & GIAA & Garuda Indonesia (Persero) tbk & Tetap \\
\hline 34 & GJTL & Gajah Tunggal Tbk & Tetap \\
\hline 35 & ICBP & Indofood CBP Sukses Makmur Tbk & Tetap \\
\hline 36 & INCO & Vale Indonesia Tbk & Tetap \\
\hline 37 & INDF & Indofood Sukses Makmur Tbk & Tetap \\
\hline 38 & INTP & Indocement Tunggal Prakarsa Tbk & Tetap \\
\hline 39 & ISAT & Indosat Tbk & Tetap \\
\hline 40 & ITMG & Indo Tambangraya Megah Tbk & Tetap \\
\hline 41 & JPFA & JAPFA Comfeed Indonesia Tbk & Tetap \\
\hline 42 & JSMR & Jasa Marga (Persero) Tbk & Tetap \\
\hline 43 & KIJA & Kawasan Industri Jababeka Tbk & Tetap \\
\hline 44 & KLBF & Kalbe Farma Tbk & Tetap \\
\hline 45 & LINK & Link Net Tbk & Tetap \\
\hline 46 & LPCK & Lippo Cikarang Tbk & Tetap \\
\hline 47 & LPKR & Lippo Karawaci Tbk & Tetap \\
\hline 48 & LPPF & Matahari Department Store Tbk & Tetap \\
\hline 49 & LSIP & PP London Sumatra Indonesia Tbk & Tetap \\
\hline 50 & MAPI & Mitra Adiperkasa Tbk & Tetap \\
\hline 51 & MDLN & Modernland Reality Ltd Tbk & Tetap \\
\hline 52 & META & Nusantara Infrastructure Tbk & Tetap \\
\hline 53 & MLPL & Multipolar Tbk & Tetap \\
\hline 54 & MNCN & Media Nusantara Citra Tbk & Tetap \\
\hline 55 & MMPA & Matahari Putra Prima Tbk & Tetap \\
\hline \multirow[t]{2}{*}{56} & \multirow[t]{2}{*}{ PBRX } & Pan Brothers Tbk & Tetap \\
\hline & & Perusahaan Gas Negara (Persero) & Tetap \\
\hline 57 & PGAS & Tbk & \\
\hline 58 & PNBN & Bank Pan Indonesia Tbk & Tetap \\
\hline \multirow[t]{2}{*}{59} & \multirow[t]{2}{*}{ PNLF } & Panin Financial Tbk & Tetap \\
\hline & & Tambang Batubara Bukit Asam & Tetap \\
\hline 60 & PTBA & (Persero) Tbk & \\
\hline 61 & PTPP & PP (Persero) Tbk & Tetap \\
\hline 62 & PWON & Pakuwon Jati Tbk & Tetap \\
\hline 63 & RALS & Ramayana Lestari Sentosa Tbk & Tetap \\
\hline \multirow[t]{2}{*}{64} & \multirow[t]{2}{*}{ SCMA } & Surya Citra Media Tbk & Tetap \\
\hline & & Industri Jamu dan Farmasi Sido & Tetap \\
\hline 65 & SIDO & Muncul Tbk & \\
\hline 66 & SILO & Siloam International Hospitals Tbk & Tetap \\
\hline 67 & SIMP & Salim Ivomas Pratama Tbk & Tetap \\
\hline 68 & SMGR & semen Indonesia (Perseto) Tbk & Tetap \\
\hline 69 & SMRA & Summarecon Agung Tbk & Tetap \\
\hline 70 & SRIL & Sri Rejeki Isman Tbk & Tetap \\
\hline 71 & SSIA & Surya Semesta Internusa Tbk & Tetap \\
\hline
\end{tabular}

Tabel 1. Data Perusahaan Pada Kompas 100 
Dengan kendala

$w_{1}+w_{2}+w_{3}+\cdots+w_{66}=1$

$0.00042214 w_{1}+0.00271764 w_{2}+0.00219129 w_{3}+\cdots$

$+0.00017219 w_{66}=0.001703146$

$w_{1}, w_{2}, w_{3}, \ldots w_{66} \geq 0$

\subsection{Formulasi Pemrograman Kuadratik}

Dari persamaan portofolio 66 saham Markowitz yang sudah dibentuk, kemudian persamaan itu dimasukkan kedalam bentuk persamaan kuadratik sesuai dengan persamaan (8) dan (9) diatas. Untuk lebih memudahkan persamaan kuadratik diubah kedalam bentuk matriks dibawah ini.

Fungsi tujuan:

$\begin{aligned} \min \sigma_{p}^{2}= & \frac{1}{2}\left[\begin{array}{cccc}w_{1} & w_{2} & \cdots & w_{66}\end{array}\right] \\ & {\left[\begin{array}{cccc}0.00160358 & 0.00008093 & \cdots & 0.00013482 \\ 0.00008093 & 0.00175066 & \cdots & 0.00011316 \\ \vdots & \vdots & \ddots & \vdots \\ 0.00013482 & 0.00011316 & \cdots & 0.00088026\end{array}\right]\left[\begin{array}{c}w_{1} \\ w_{2} \\ \vdots \\ w_{66}\end{array}\right] }\end{aligned}$

Dengan kendala

$\left[\begin{array}{cccc}0.00160358 & 0.00008093 & \cdots & 0.00013482 \\ 0.00008093 & 0.00175066 & \cdots & 0.00011316 \\ \vdots & \vdots & \ddots & \vdots \\ 0.00013482 & 0.00011316 & \cdots & 0.00088026\end{array}\right]\left[\begin{array}{c}w_{1} \\ w_{2} \\ \vdots \\ w_{66}\end{array}\right]$

$\left[\begin{array}{llll}1 & 1 & \cdots & 1\end{array}\right]\left[\begin{array}{c}w_{1} \\ w_{2} \\ \vdots \\ w_{66}\end{array}\right]=1$

$\left[\begin{array}{llll}0.0004221 & 0.00271764 & \cdots & 0.00017219\end{array}\right]\left[\begin{array}{c}w_{1} \\ w_{2} \\ \vdots \\ w_{66}\end{array}\right]=0.001703146$

\subsection{Portofolio Optimal}

Persamaan kuadratik diatas diselesaikan menggunakan bantuan software matematika. Dimana didapatkan hasil sebagai berikut.

\begin{tabular}{|c|c|c|c|c|c|}
\hline \multicolumn{6}{|c|}{ Tabel 4. Hasil Bobot } \\
\hline No & $\begin{array}{l}\text { Kode } \\
\text { Saham }\end{array}$ & $w$ (Bobot) & No & $\begin{array}{l}\text { Kode } \\
\text { Saham }\end{array}$ & $w$ (Bobot) \\
\hline 1 & AALI & $1.40 \mathrm{E}-19$ & 34 & INCO & $2.91 \mathrm{E}-19$ \\
\hline 2 & ACES & 0.007867305 & 35 & INDF & $6.59 \mathrm{E}-19$ \\
\hline 3 & $\mathrm{ADHI}$ & 0.006737201 & 36 & ISAT & 0.063283909 \\
\hline 4 & ADRO & 0.005417966 & 37 & ITMG & $-9.24 \mathrm{E}-21$ \\
\hline 5 & AISA & 0.019186377 & 38 & JPFA & 0.002616092 \\
\hline 6 & AKRA & 0.039436348 & 39 & KIJA & 0.008461274 \\
\hline 7 & ANTM & 0.043687026 & 40 & KLBF & $-1.27 \mathrm{E}-18$ \\
\hline 8 & APLN & 0.009955717 & 41 & LPKR & 0.009587947 \\
\hline 9 & ASII & $-7.44 \mathrm{E}-20$ & 42 & LPPF & 9.07E-05 \\
\hline 10 & ASRI & $6.05 \mathrm{E}-19$ & 43 & LSIP & 0.019784767 \\
\hline 11 & BBCA & 0.050777388 & 44 & MAPI & $7.70 \mathrm{E}-19$ \\
\hline 12 & $\mathrm{BBNI}$ & $-7 \cdot 38 \mathrm{E}-20$ & 45 & MDLN & 0.012055587 \\
\hline 13 & BBRI & $-1.18 \mathrm{E}-18$ & 46 & MLPL & $9.63 \mathrm{E}-19$ \\
\hline 14 & BBTN & 0.060733454 & 47 & $\mathrm{MNCN}$ & $3.43 \mathrm{E}-19$ \\
\hline 15 & BCIP & 0.059027827 & 48 & PGAS & $-2.25 \mathrm{E}-18$ \\
\hline 16 & BDMN & $-1.96 \mathrm{E}-20$ & 49 & PTBA & $6.48 \mathrm{E}-19$ \\
\hline 17 & BEST & $-6.99 \mathrm{E}-19$ & 50 & PTPP & 0.025041438 \\
\hline 18 & BJBR & 0.010250884 & 51 & PWON & $5.99 \mathrm{E}-19$ \\
\hline 19 & BJTM & 0.02866956 & 52 & RALS & 0.020223873 \\
\hline 20 & BKSL & 0.0079143 & 53 & SCMA & $6.08 \mathrm{E}-18$ \\
\hline 21 & BMRI & $4 \cdot 35 \mathrm{E}-19$ & 54 & SIDO & 0.078652122 \\
\hline 22 & BSDE & $-4.53 \mathrm{E}-19$ & 55 & SIMP & 0.014292467 \\
\hline 23 & BUMI & 0.016730927 & 56 & SMGR & $-2.36 \mathrm{E}-18$ \\
\hline 24 & BWPT & 0.002021084 & 57 & SMRA & $-2.30 \mathrm{E}-18$ \\
\hline 25 & CPIN & $5.45 \mathrm{E}-19$ & 58 & SSMS & 0.031338831 \\
\hline 26 & CTRA & $1.04 \mathrm{E}-18$ & 59 & TARA & 0.073006652 \\
\hline 27 & DILD & 0.050557122 & 60 & TINS & $4.08 \mathrm{E}-18$ \\
\hline 28 & ELSA & $2.66 \mathrm{E}-20$ & 61 & TLKM & 0.048622779 \\
\hline 29 & EXCL & $-2.92 \mathrm{E}-19$ & 62 & UNTR & $2.60 \mathrm{OE}-18$ \\
\hline 30 & GGRM & 0.028794086 & 63 & UNVR & 0.020009827 \\
\hline 31 & GIAA & 0.03436365 & 64 & WIKA & 0.001752314 \\
\hline 32 & GJTL & 0.014116286 & 65 & WSKT & 0.07067089 \\
\hline 33 & ICBP & $1.40 \mathrm{E}-19$ & 66 & WTON & $8.40 \mathrm{E}-19$ \\
\hline
\end{tabular}

Dari hasil pada tabel 5 , bobot $(w)$ sendiri menandakan bahwa seberapa besar dari total dana investor yang harus diinvestasikan pada saham. Hasil didapatkan bobot terbesar di peroleh oleh saham dengan kode SIDO yaitu sebesar 0.078652122. dan bobot terkecil diperoleh oleh saham dengan kode SMGR yaitu sebesar -2.36E-18. Nilai ini menunjukkan bahwa investor dapat mengalokasikan sejumlah dananya pada saham SIDO sebesar 0.078652122 dari keseluruhan alokasi dana investor. Sedangkan untuk saham SMGR nilai bobot $(w)$ bernilai negatif yaitu sebesar -2.36E-18, maka investor yang ingin mengalokasikan sejumlah dananya pada saham SMGR akan mengalami short selling.

\section{KESIMPULAN DAN SARAN \\ 5.1 Kesimpulan}

Portofolio optimal diperoleh dengan mengalokasikan sejumlah dana pada 66 saham sesuai dengan bobot $(w)$ yang diperoleh pada hasil. Dengan tingkat keuntungan portofolio sebesar 0.002703146 , nilai bobot tertinggi diperoleh oleh saham dengan kode saham SIDO yaitu sebesar 0.078652122 sedangkan nilai bobot terendah diperoleh oleh saham dengan kode saham SMGR yaitu sebesar -2.36E-18. Nilai bobot $(w)$ yang negatif pada saham menunjukkan terjadinya short sell pada saham tersebut.

\subsection{Saran}

Bagi investor dalam pemilihan investasi saham sebaiknya mengalokasikan seluruh dananya tidak hanya pada satu saham/perusahaan saja tapi beberapa saham, agar tingkat keuntungan yang didapatkan lebih besar dengan resiko yang kecil berdasarkan portofolio yang dibentuk.

\section{REFERENSI}

[1] Halim, A. 2003. Analisis Investasi. Salemba Empat, Jakarta.

[2] Tandelilin, E. 2017. Pasar Modal Manajemen Portofolio dan Investasi. PT Kanisius, Yogyakarta.

[3] Sunarriyah. 2004. Pengantar Pengetahuan Pasar Modal. Edisi Keempat. UMP AMP YKPN, Yogyakarta.

[4] Hartono, J. 2015. Teori Portofolio dan Analisis Investasi. BPFE, Yogyakarta.

[5] Wang, Jiang. 2003. Lecture Notes : Portfolio Theory. Fall

Winston, W.L. 2004. Operation Research Aplications And Algorithms. Fourth Edition. Thomson Learning, Inc, Canada.

Hiller, F. S and Lieberman, G. J. 2001. Introduction To Operations Research. Seventh Edition. McGraw-Hill, Inc, Singapore.

Bursa Efek Indonesia. http://www. idx.co.id/pPortals/o/StaticData/Market Information/ListOfSecurities/IndexCo mstituent/Kompas100/20150729 Pengo0699 BEI.OPP O7 2015.pdf $[26$ Januari 2017].

[9] Saham Kompas 100. http://www. sahamok.com/bei/kompas-10o/amp/ [26 januari 2017]

[10] Yahoo Finance. http://www.finance. yahoo.com [18 februari 2017].

[11] Rindengan, A dan Langi, Y. 2018. Program 
Shintya Gayanti Filrissa, Jullia Titaley, Tohap Manurung

d'Cartesian : Jurnal Matematika dan Aplikasi, Vol. 8 No.2 (September 2019): 121-126

Linear. CV Patra Media Gravindo,

Bandung.

[12] Ibrahim, M. 2017. Analisis Keakuratan Capital

Asset Pricing Model (CAPM) dan Arbitrage

Pricing Theory (APT) dalam Memprediksi

Expected Saham pada LQ45. Jurnal

d'Cartesian. Vol 6(1):31-44

Shintya G. Filrissa_(shin.filrissa@gmail.com)

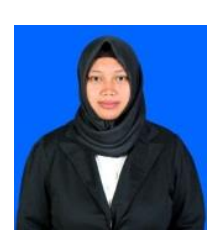

Lahir di Inobonto, 13 Oktober 1994. Menempuh pendidikan tinggi Jurusan Matematika, FMIPA, Universitas Sam Ratulangi Manado. Tahun 2019 adalah tahun terakhir ia menempuh studi. Makalah ini merupakan hasil penelitian skripsinya yang dipublikasikan.

Tohap Manurung (Tohapm@unsrat.ac.id)

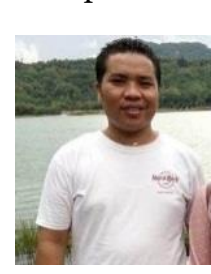

Lahir di Toba, 24 Desember 1979. Pada tahun 2010 memperoleh gelar Magister Sains (M.Si) dari Institut Teknologi Bandung. Menjadi pengajar tetap di Jurusan Matematika, Fakultas Matematika dan Ilmu Pengetahuan Alam Universitas Sam Ratulangi Manado.

Jullia Titaley(july_titaley@unsrat.ac.id)

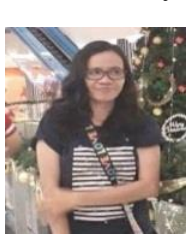

Lahir di Ambon, 18 Juli 1972. Pada tahun 2001 memperoleh gelar Magister Sains (M.Si) dari Universitas Gajah Mada. Menjadi pengajar tetap di Jurusan Matematika, Fakultas Matematika dan Ilmu Pengetahuan Alam Universitas Sam Ratulangi

Manado. 